\title{
Growing Up Without a Father and a Pursuit for the Right Surname
}

\author{
Mzikazi Nduna*
}

Department of Psychology, University of the Witwatersrand, 1 Jan Smuts Avenue, Braamfontein, Johannesburg, 2000, South Africa

\begin{abstract}
Young people who grew up without their biological fathers may or may not use their surnames. This paper contributes to an understanding of young people's views of the relevance of a biological paternal surname. We conducted gender-matched in-depth interviews with 73 volunteers aged 14-39 in two South African provinces and transcribed and translated audio-recorded home language interviews into English. The findings indicate that the pursuit for using a biological father's surname was motivated by seeking ancestral protection, seeking one's father so that he could play an overseeing role in rituals, and citizenship rights; some participants believed that the use of a biological father's surname was essential for registration for an identity document, passport, marriage and death certificate. However, there was no agreement in the data about the importance and usefulness of using a biological father's surname. In conclusion, the article maintains that the father's surname is important for some children who grew up without their fathers.
\end{abstract}

Keywords: Absent father, father, qualitative research, South Africa, surname, tradition.

\section{INTRODUCTION}

The South African government recently ended the issuing of abridged birth certificates in favour of the unabridged certificate that contains the names and identity numbers of both the mother and father of the newborn [1]. However, the phenomenon of children growing up without knowing their biological fathers is not going to go away soon. Names of fathers for children born before March $4^{\text {th }} 2013$ may not be registered, some fathers may disappear from their children's lives despite their names being known registered and some women choose not to register a father on the birth certificate (see [2-4]). In this article, 'father' refers to a biological father unless otherwise stated. There are limitations to knowing ones father (the genitor] as this status is not obviously determined by a natural process of giving birth as with the mother (the genetrix) [5]. Some children who grew up not knowing their father seek to find them and may reclaim their paternal identity by changing their surnames as a father's surname is considered important in many African communities [2, 6-10].

There is no cultural pureness or authenticity in the practice of surnames in sub-Saharan Africa. However, surnames carry significance in cultural personal identity, while problems around surnames seem to create a perpetual sense of dissatisfaction and feelings of disenfranchisement among some Africans [10-12]. For children born out-ofwedlock, acknowledgement of paternal responsibility for the pregnancy sometimes links to the child taking on the father's name. Traditional rituals, such as imbeleko, are performed on the father's side to introduce the child to their paternal

*Address correspondence to this author at the Department of Psychology, University of Witwatersrand, 1 Jan Smuts Avenue, Braamfontein, Johannesburg, 2000, South Africa; Tel: +27 11717 4168;

Fax: +27 11717 4559; E-mail: Mzikazi.nduna@wits.ac.za ancestors so that the child can legitimately claim their paternal ancestry [13].

Some mothers, fathers, guardians and children alike, express a worry and a belief that not using a biological father's surname could have negative repercussions for the child and may cause personal problems and bad luck [2, 6, 13]. Literature describes that traditional initiation confronts some Xhosa boys with shame for not using their father's surname. This initiation is a ritual which includes circumcision and seclusion of boys and marks a transition from boyhood to manhood $[12,14]$. In other contexts, such as in Europe, searching for one's father may be in the interest of identity [15]. In South Africa, taking on a father's surname fosters a legitimate identity that gives a child access to their father, paternal uncles and family lineage [7, 13]. This may be the case even if the child did not know his father [9].

The essentialisation of a father's surname is not uncontested as some people find that they are unable to use his surname for various reasons [9]. Single-mother-parented households are a norm in sub-Saharan Africa and mothers "...give their last names to their children...[10]". There is evidence that children receive ancestral protection and guidance from both the mother's and father's side of the family [16]. Nonetheless, as children grow, some question why they are using their maternal surname $[6,17]$. Though international theories of adolescence are extensive, academic research on the importance of a father's surname is minimal. A South African study on Father Connections examined the question of a father's surname.

\section{METHOD}

\section{Study Design and Site}

The study was qualitative and exploratory. Study Site 1 was the Gert Sibande District in Mpumalanga Province, 
about 133 kilometres away from the city of Johannesburg in South Africa. About $30 \%$ of the people in this province speak siSwati, with $26 \%$ speaking isiZulu, $10.3 \%$ isiNdebele, $10,2 \%$ Northern Sotho and $11,6 \%$ Xitsonga. The town where the study occurred, Secunda, occupies $2,955 \mathrm{~km}^{2}$ and in the 2001 census it had a population of 221,739 people. The study occurred in the township of Embalenhle. Study Site 2 was in the Siyanda District of the Northern Cape, some 788 kilometres away from Johannesburg, in Upington. Ethnicity and language identify most people here as Coloured. They speak mainly Afrikaans and there are some Xhosa and Setswana speaking people who relocated from the Eastern Cape and Kuruman, respectively [18, 19]. The term Coloured is used in this paper in its historical context to refer to people of mixed descent with acknowledgement that it is not necessarily accepted by all persons concerned [19]. The study occurred in the township of Paballelo.

\section{Study Participants and Recruitment}

Field workers recruited study participants from the local townships through snowballing. More information about the field workers and recruitment presents elsewhere [20, 21]. A 'Township' in South Africa refers to an urban residential area that was created for black migrant labour during the previous apartheid government regime and are usually found beyond the town or city limits with numerous kinds of dwellings such as one-roomed houses, larger four-roomed houses, shacks, backyard shack and flats [14, 22-24]. Generally, every town/city has one or several townships associated with small dwellings densely packed within the community [25]. South Africa, as with many other African states, is a collection of ethnic groups or micro-nations [10]. We conducted these interviews in communities that were multi-ethnic owing to them being migrant towns. The field workers developed an information pamphlet for the study, written in simple English devoid of scientific jargon, and they distributed it widely in the community. We presented the study verbally to local stakeholders including schools, non-governmental organisations (NGOs), social workers, clinics and youth centres. We collected 73 recorded and audible interviews. Participants consisted of a mixture of high school learners, students at further education institutions, employed and unemployed youth. This study brings the youth's perspective to many voices already influencing the way we understand the experience of father absence. Below is a table summarising the ages of the participants.

Participants were Coloreds, Zulu, Sotho, Ndebele and
Swati. Though many were of mixed couples, they based their identification on their primary parent's (mother) ethnic group, spoke a language primarily spoken at home and yet some referred to the ethnic group of the absent unknown father as their social identity.

\section{The Interviews}

Field workers were recruited and trained for this study. The field workers were young and Black, from different ethnic groups. They grew up in similar townships as participants and collectively represented the multilingual characteristics of the participants [26]. Each field worker conducted between 16 and 20 gender-matched, in-depth, one-on-one, face-to-face interviews with women and men aged 14-39 years. The narratives of absent fathers may contain sensitive information and so need to be approached with care [2]. Hence the gender-matched interviews as they assist in dealing with the gender power dynamics during interviewing, and also strengthen data credibility as they are observed to allow for more honest disclosure [27]. To encourage free narratives, we chose an open interview style with a few open-ended questions formulated in advance to guide the discussion [28]. We asked all questions in the participant's home language or English if so chosen. The interview opened with a general question asking each respondent to state the reason why he or she agreed to participate in the study; this got the respondent's story going. Depending on their story, relevant probing followed. We present more information about the procedures and processes of data collection elsewhere [20,21].

\section{Data Management: Translation and Transcription}

Ethnicity based on spoken language divided the communities; field workers were able to handle this, as they were familiar with more than one culture and language. The same field workers who conducted the interviews transcribed all the audio-recorded interviews as far as possible in Mpumalanga. As this was not possible with audio-recorded interviews from Siyanda two independently contracted Afrikaans-speaking, White, bilingual, graduate students from the University transcribed these interviews. There is no reason to believe that contracting translation compromised the data as research shows that Afrikaans grammatical norms adhered to by Afrikaans-speaking White South Africans and Coloureds converge and young Afrikaans-speaking Africans from Siyanda District do stick to prescriptive standard Afrikaans in their speech [19].

\section{Data Analysis and Interpretation}

Table 1. Age, education and employment status of the participants.

\begin{tabular}{|c|c|c|c|c|}
\hline & \multicolumn{2}{|c|}{ Site 1: MP } & \multicolumn{2}{|c|}{ Site 2: NC } \\
\hline Grade 12 and below & 17 & 17 & 6 & 10 \\
\hline Tertiary Education & 1 & 1 & 1 & \\
\hline Employed & 1 & & 1 & \\
\hline
\end{tabular}


The sub-theme referring to the use of a surname became significant during coding of the data. The author of this paper undertook textual content analysis of the data that referred to the use of a surname. During content analysis I examined how referral to one's surname reflected social and cultural values and phenomena and represented the significance of a biological father. Textual analysis is an interpretative activity that involves examining the transcribed text and raising questions about what is included and what to exclude. Textual content analysis recognises that representations of reality have embedded in them particular views of the world or ideologies that relate to questions of power in society. I grouped the participants' content in two: a narrative that suggested a pursuit of a father's surname and a narrative of those participants who were comfortable with their maternal surnames and did not pursue a father's surname. This paper focuses on the former.

\section{Ethical Considerations}

The University of the Witwatersrand's ethics Committee for Research with Human Subjects Ethics granted approval for the study. Participants signed a consent form and gave permission to an audio-recorded interview and use of quotations from their narratives. All participants received a R50.00 (US \$5.7 in 2012) reimbursement. While monetary incentives may motivate volunteers to participate in research [29], this small amount could not have unduly enticed participants $[30,31]$. Pseudonyms replaced participants' and family members' names in preparation for transcription and to protect their identities. All participants' audio-recorded data were deleted from the audio recorders and saved in a password-protected file on the principal investigator's (PI) computer. Only members of the research team have an access to the data. Prior to collecting data, field workers were thoroughly trained, on the research process and training continued throughout the fieldwork support, regular meetings with the PI, and debriefing sessions with the whole research team. The field workers gave permission for the recording and transcription of debriefing meetings, and notes from these meeting contributed some data. Other publications refer to more information about this process $[20,21]$. To increase study credibility and trustworthiness the study team gave presentations about the project to varied audiences and received feedback that strengthened interpretation of findings.

\section{Findings}

Some participants who referred to the use of their mother's surname to be the wrong surname evoked belonging to a clan and family culture and represented it as static. In this section, I present three main themes that emerged in the discourse about pursuing the father's surname: i) a perception and a belief that a father's surname was appropriate for ancestral protection, ii) a perception and a belief that a father's surname was appropriate in order to have the right person(s) preside over one's traditional rites, and iii) a perception and a belief that a father's surname was appropriate for the rights of citizenship.

\section{Generativity and Ancestral Protection}

Some participants linked their assertions to possible foreseen problems with generativity, access to ancestral protection and citizenship rights. Hence talking about one's legitimate surname and future were dominant motivations for the pursuit of finding and knowing one's biological father. For example, Noluthando (female, 16, Mpumalanga) grew up in her maternal home after her father left her mother when she was two months old. Noluthando felt that her future was in jeopardy because she was using 'the wrong surname', which she worried,"...that I use my mother's surname...you see and I don't know how I am using my mother's surname and why...you really have to know who you are and where you come from..." This participant expressed, through the use of 'how' and 'why' questions, the use of a maternal surname as if to suggest that it should not be this way and there should be an explanation. She linked her questioning to a quest for knowledge of her origins and personal identity.

Another participant, Joe (male, 19, Mpumalanga), expressed that he did not know his father; he had never seen him though people talked about his resemblance of his father. Joe used his mother's surname and yet expressed that, “...my children cannot use my mother's surname...." Joe's mother was Swati and his father was Ndebele. He regarded himself as Swati and emphasised that he was not interested in the Ndebele culture but in his father's surname. Joe wished to have his own children in future and for him, it would be wrong if his children continued with their maternal family as he felt he was wrong to continue to use his mother's surname. He said:

"...what will restrict me is that I would first have to find my father before I can do all of that, use his surname and then I can have a family. Because if my children would have to be called by my mother's surname and I'm also called ((his mom's surname)) they won't know themselves where they come from, even their children will be called ((his mom's surname))..."

Interviewer: "if you don't find your father do you think that would be a big problem in your life, and would that restrict you from having a family?"

Joe: "It would be a problem- a big problem if I don't find him."

As Joe said in the quotation above that if he did not find his father and changed to his rightful surname that, "...would be a problem- a big problem..." for him when the time arrives that he takes a wife.

Jacob (male, 21, Mpumalanga] did not know his father. He used, like others, his mother's surname. He knew his father's surname because his mother had told him. Jacob spoke a lot about faith and prayer during the interview and when the interviewer asked him about one thing that he prayed for he said, "...I pray and I believe that one day he will turn up. I don't even care about the other stuff, I just want to get to know him and know my other family then it is fine so I can change my surname..." Jacob explained the reason for his interest in changing his surname to his father's as, “... I am getting older...even now, one day it might catch up with me on a lot of things. If I have a child, they can't have my mother's surname and I don't know my surname so 
which surname will I use...?' Jacob's narrative echoed Joe's in relation to generativity and the 'correct' identity. Jacob said he had told his mother of his intention to change to his father's surname and she did not have a problem with that. This suggested serious consideration for the pursuit for the right surname. 'Right' here indicates that these participants regarded use of the maternal surname by themselves as 'wrong'. Some of the participants who had found and reconnected with their fathers before participating in the study had changed surnames from their mothers' to their fathers'. A traditional ritual to introduce the participant to their paternal ancestors accompanied most of these surnamechanging processes.

Some participants seemed to believe that they needed a biological father's surname when applying for an identity document (ID], a passport and a marriage or death certificate. Boitumelo (female, 18, Mpumalanga] did not know either of her parents and stayed with guardians who were not blood relations of hers. In the interview, she emphasised that, "...I want to know who am I, where I come from so that when I am older I must not have problems so I would like to know that..." When asked by the interviewer what sort of problems she envisaged she responded that, "...you see when you are getting married, things like that they want your real surname or when you die your real surname is needed, not other people's surname..." 'They' here referred to the Department of Home Affairs officials. Boitumelo gave other examples of the importance of using her father's surname citing that, “...maybe when they say you are going to register somewhere I want... maybe if you wanted to look for my parents they would want my surname ..." Boitumelo did not know her parents but her guardian knew the surname of her father and when they applied as her foster parents they used her father's surname for her.

In some cases, where the participant did not know their father, they sometimes knew his surname but could not use it. For instance, Nomthandazo, (female, 16, Mpumalanga) who did not know her father as she said "...sometimes when I hear people say that they are Zulu [ethnic group] I sometimes ask them their surnames ... when I see that a person has the same surname as me (meaning her father's) I feel like we are related..." Feeling affinity to a group of 'strangers' is possible as described in studies of ethnicity because of the emotional appeal of ethnic identity that stresses security and familiarity [26]. Nomthandazo said once she found her father she would change to his surname, "...after I know him for some time..." because, "...it will affect me at school..." and so this was an administrative hurdle. Some participants were interested in pursuing the right surname and changing to it as Nokwazi (female, 18, Mpumalanga] who shared her maternal surname with her class teacher said that the teacher fondly commented on being her namesake when she announced her grades in class. Nokwazi felt that, "...it would have been better if it was my surname..." suggesting discontent that it was her mother's surname and saying, "... it would have been better if there was something that I can do to change this thing...". 'This thing' here referred to using her mother's surname:

“...Because I even asked my mother if it will be possible for me to go back to my surname and she said yes it can happen. That would be your father, if he would agree, and do all the rituals that need to be done..."

At the time of the interview, Nokwazi was looking to find her father, "...because I know that the surname I am using is not mine..." and her interest in knowing her culture motivated her.

Some of the participants used their fathers' surnames but deemed these surnames inappropriate. For instance, Tsakane (female, 16, Mpumalanga), who grew up with her mother's side of the family but has always used her father's surname, shared that, "...In fact the surname that I am using is not mine it's my grandfather's surname..." Tsakane's paternal grandfather took on his maternal surname and this is where she considered things to have gone wrong. Tsakane insisted that, “... Truthfully, I am a Dubula, like my grandfather took his mother's surname. Then we (grandchildren] carried on with the surname and his children (Tsakane father)...but rightfully my grandfather is a Dubula, but because of his father... but they said we will change it. When I don't know.

\section{PM: "so Tom is your father's surname" \\ Tsakane: "yes for now he is Tom"}

In her case, even though her biological father had never paid Inhlawulo to her mother's family they had an agreement that allowed her to use her biological father's surname. Inhlawulo refers to compensation paid for 'damages'to the family of a woman who became pregnant out of wedlock by the father of the future child. Tsakane considered her father's surname not befitting as her grandfather (her father's father) had taken his maternal family surname and as such messed up the family lineage. In bride wealth societies men pay for access rights to their offspring through inhlawulo [5]. Bride wealth societies are those where a woman is married off to a man through payment of a 'bride price' as is the case in most South African Black communities. Tsakane emphasised that 'for now' they used (as family) the wrong surname hoping for the correction of this mistake. Others also confirmed the importance of a father's role in tradition and cleansing in the Zulu culture.

\section{Ancestral Protection and Presiding Over Traditional Rituals}

There was a notion that one's father was the right person to preside over traditional ceremonies and rituals such as marriage processes. A traditional calling to be a Sangoma (ithwasa calling) is one of the rituals which deems a biological father as important. For instance Thabo (male, 20, Mpumalanga), who did not know his father, and learned that he had died a year before the interview said:
“...the surname I'm using is not my father's because my mother was not honest with me...so I had to use my mother's surname and... This thing makes me feel...somehow... I can't even explain it to you..."

The talk about the surname, as in many other interviews came spontaneously but when the interviewer asked Thabo his thoughts about linking his identity to his surname he said:
“...I'm Swati and this thing means a lot in life
spiritually...In my family I got a prophecy
from someone that I am this and that... There 
is a prophet in my body, (my body) was itching. Therefore, they would tell me that ... the way to solve this is through my ancestors. 'So your grandfather passed on some of his gifts to you and they just stayed inside your body...It is not that you have done this to yourself; it is your background that is catching up with you'. It's the surname that is wrong..."

'This and that' referred to the calling to be a traditional healer. A spiritual blessing to be a healer is the 'gift' that Thabo referred to. There is existential contradiction here as Thabo regarded his calling as both a blessing and a burden. The sickly symptoms associated with the calling is what Thabo saw as a burden that resembled a punishment that he suffers as a result of using his maternal surname, a 'wrong' surname. Thabo went on to explain how much this affected his day-to-day life:

"I know that what I am saying is deep...My culture requires me to be someone that the spirit chose me... But there is no one to do those things for me but they told me that I need to do whatever my culture dictates and everything will go well. And it's true because now things are going slowly. So even when I'm writing exams it feels as though there's something that's distracting me. It sounds like the ruffle of trees and that thing can take my vision and put it elsewhere. I can be here but this thing can take me somewhere else and people will be calling me 'Thabo, Thabo, Thabo' and I'm not even there you see. Sometimes it comes across as though I'm mentally disturbed but no it's a visual thing...It's private but I'm telling you because it really bothers me because of the whole ((surname)) situation. You know what I did? I undermined culture and tradition and so it came back to bite me..."

Thabo said his ithwasa calling,

“...comes from my father's side. So the thing is the man who was my father's father was an 'inyanga' (traditional healer) ..."

\section{DISCUSSION}

The aim of this paper is to understand the importance of the paternal surname for young people from South Africa. Our findings affirmed the value placed on the paternal surname by young people who, because of the absence of fathers for various reasons, have carried their maternal surnames. The participants saw this as important for rituals, cleansing ceremonies and marriage processes. Furthermore, the correct surname was perceived to create a spiritual connection based on paternal lineage and legitimised a sense of identity. A need to know one's father appears important for girls and boys, and women and men [see also, 6, 14]. Children do not always seek to live with their absent biological fathers as it is not his absence per se that is a problem but that children need to know their fathers; maternal families and mothers may not always be sure how to handle this problem $[2,6]$.

\section{Lineage for Children who Grew Up Not Knowing their Biological Fathers}

Some participants considered being raised under the maternal surname as de-cultured and inappropriate hence they disowned, undermined and invalidated the use of their mother's surname. For these participants, a surname had relevance and practical connotations. One of them is legitimacy given to a paternal lineage and linked to the clan name; an identity considered to be important in some Black African micro-nations as seen in Spiegel et al. [22]. It is not only psychological science that seems to pathologise the absence of a biological father as concluded by Clowes et al. [32], but from a traditional point of view disconnection from paternal ancestry is considered as a problem $[6,13]$. Current findings suggest that (re) discovering and (re) connecting with one's father enhances self-knowledge and can provide individuals with deep psychological and spiritual clarity. It would seem that the importance of a connection to a father is not about the perpetuation of the ideology of a nuclear family per se as suggested in other research [32] but more so, some South Africans need a father and to use his surname for a sense of belonging to the 'right family'. An idea that the importance of a biological father is an idealised myth, "...that creates the narrative of deficit..." [32] negates the traditional circumstance of many from various South African ethnic groups for whom a biologically connected father is equated with ancestral spiritual connection and deemed important by both fathers and children $[6,13]$.

Findings from this study suggest that participants seemed to reject a culture that commodifies access to a father's surname through Inhlawulo as a pre-requisite, and thus create a new culture of claiming a father's surname in instances where they were aware that he did not offer Inhlawulo to acknowledge pregnancy. This could be because being raised using a mother's surname may make one stand out as a 'bastard' and participants seemed to reject that being born out-of-wedlock meant that they were illegitimate. The presence of social fathers, in the form of elder brothers, uncles, step-fathers, neighbours and others, in the lives of participants in this study did not seem to close the gap as a connection to a biological father and his surname seemed imperative. This is reported elsewhere as well [13].

\section{Misfortunes and Lack of Ancestral Protection}

There seemed to be a belief from these, and other findings, that failure to use one's paternal surname meant loss or lack of ancestral protection which was believed to potentially impact, negatively and disastrously, in one's life and bring misfortune [2, 13]. The main areas of life considered as premeditated by ancestral spiritual protection were success at school, securing a job, health, relationship with partner and marriage.

The linkage between misfortunes and lack of ancestral protection here seemed simplistic and oblivious of a multitude of macro problems facing young people who grow up in townships. For instance, some fathers may not be working and hence they experience unemployment as a constraint to exercise fatherhood [13]. Townships in South Africa are not only physical locations but spectacular sites where violence, crime, gangsterism, substance abuse, poverty and complex moralities are rife; they are sites of 
economic and social exclusion and inequality and these produce negative outcomes for young people who grow up in them [14, 23, 24, 33, 34].

Many township children in primary school are subjected to a cycle of failure, mobility, dropout and re-entry into school, hence, only a fraction manages to finish high school, an even smaller proportion secures a university entry and a very small proportion is able to attend university [14]. At universities, the throughput for Black African students is low. South Africa has a large number of young people of working age who are not in employment, Training and not in School (NETS). The problem of unemployment is a bigger sociological and economic problem that emanates from poor township education which fails to prepare matriculants for the job market [14, 34]. The two provinces, as base of the study, also face these challenges.

The general health of young people in South Africa is a national problem. Young people account for much of the high HIV prevalence; the Mpumalanga province has the second highest HIV prevalence in the country, reported to be at $35.1 \%$ by the National Department of Health's antenatal survey and at $15.4 \%$ by the HSRC's General Household Survey and Black African youth are the worst affected [35]. AIDS continues to be the leading cause of death in South Africa, responsible for about $40.5 \%$ of all deaths and the Mpumalanga province where the study was carried out has a lower comparing life expectancy (50.2 for males and 50.8 for females) [36]. In Embalenhle young people are reported to suffer ill-health problems resulting from many toxic pollutants emitted from the coal mines, refineries and several downstream chemical industries that Sasol operates in the town of Secunda [23, 37]. Against this backdrop, it may seem simplistic to assume that the widespread problems of youth unemployment and morbidity links directly to lack of ancestral protection.

Getting married is an important milestone for young adults in the SA community. To have, keep and maintain a relationship is taken to be very important by some youth [38]. Nonetheless, research on the status of families reports that registered marriage rates are low among Black African people [39]. A number of factors are accounted for this such as migration, financial constraints, careering, changing societal norms around sex and marriage. Separation of biological parents can also result from divorce [40]; a common occurrence in South Africa. Nevertheless, the finding that paternal ancestral blessings predetermine success in marriage and family life withstand this knowledge.

In this study, a process of attributing a dissatisfactory state to external powers was evident through the belief in the important role of paternal ancestors. Youths' beliefs in this study seem different from those of meritocracy (a belief in being personally responsible for escaping poverty through hard work) as reflected by young people in a study of morality outside Cape Town [14]. This departure from the quixotic hopefulness and a strong belief in meritocracy in this sample could be due to strong beliefs in supernatural forces by participants. This study demonstrates that there may be no amount of scientific research evidence used to understand embodied beliefs in spiritual protection and dispensation of bad luck following failure to observe one's right culture. For those who believe in paternal ancestral protection, this is their lived reality. The failure to critically engage with the socio-political forces that drive township misfortunes is seen in youth, and others, from similar townships $[14,41]$. This is important to engage with as such externalising attributions can easily distract some young people and make way for attributions that may undermine a focus on internal locus of control and adoption of agency and health promoting behaviours. Pursuit of the right father's surname to facilitate ancestral protection seems in conflict even with knowledge that actually some children raised on their mother's side of the family can get protection and guidance from their maternal ancestors [16]. However, evoking the discourse of individual agency and meritocracy may have a potential to pathologise their narrative as backward, traditional, underdeveloped, disempowered, essentialist and morally inferior. The discourse of agency implicitly communicates middle-class assumptions about the independent, self-directed individual as an agent of their own progress and emancipation.

\section{STUDY LIMITATIONS}

A voluntary discussion of a surname was less pronounced and even nil in the interviews conducted in Upington The young age of participants meant that they might not have been privy to the right kind of information about applying for birth, marriage and death certificates, identity and passport documents. Hence the misperceptions that a father's surname is needed for such documentation to be issued.

In this study, the author used textual content analysis as a method of choice. With this comes recognition that reading texts is an act of interpretation and interpretation has a subjective dimension, so these findings are amenable to that finding. This approach can subject text to fragmentation, and yet in order to understand texts, one needs to take into account relations between the part and the whole. I tried to do this in the discussion but in hindsight, by so doing, the approach could compromise symbolic dimensions of the data.

\section{CONCLUSION}

This paper adds to the body of knowledge about the relevance and importance of a biological father. It would seem from this paper that some children who grew up under their maternal guardianship considered adopting a biological father's surname legitimate, claiming paternal identity could be a self-liberating journey. The pursuit of a father's surname by children born out-of-wedlock contributes to change in a practice of assigning paternal names exclusively to children born in matrimony. Practitioners working with children and researchers should appreciate the satisfaction that comes with owning this part of one's cultural and personal identity for those affected. Mothers should be equipped with ways of communicating about an absent and unknown father in families and that extends to equipping them for the ultimate possibility that their children would change their surnames and mothers should not interpret this as betrayal $[2,3]$.

At the time of writing this paper, there was no official policy that mandates South African citizens to use their 
father's surnames to apply for a birth or death certificate, identity document, passport, marriage certificate or any other official document. However, there are reports of unofficial demands made by some government representatives who require that single mothers registering their children at school or guardians applying for a child support grant should produce the father's ID or proof of death [2, 42, 43]. These unscrupulous practices create misinformation and confusion in the community and hence the misconception of the need to use the same surname as one's father to get the required documentation. To allay some anxieties, public education need to inform people about what is required to register marriages, apply for identity and passport documents and death certificates as these can be granted even when an applicant uses his/her mother's surname. Participants were younger and hence inexperienced in dealing with the Department of Home Affairs. However, adults have some misconceptions and some children are the heads of their households therefore, there is a need for public education for all.

\section{CONFLICT OF INTEREST}

The author confirms that this article content has no conflict of interest.

\section{ACKNOWLEDGEMENTS}

I am grateful to the XXXICP2012 for the CHANGE Fellowship fund, the Jacobs Foundation, the National Research Foundation of South Africa and IUPsyS. I thank the study participants for their time and contribution of data. I thank my colleagues who are members of the Father Connections research team, Grace Khunou, Yandisa Sikweyiya, Thandeka Mdletshe, Vuyani Pambo, Tidimalo Padi, Motlalepule Nathane-Taulela and Priscilla Gerrand for their support in the execution of this study.

\section{REFERENCES}

[1] Department of Home Affairs. Minister Naledi Pandor ends the practice of the issuance of abridged birth certificates Pretoria: Department of Home Affairs 2013 [cited 2013].

[2] Manyatshe L. Why mothers won't tell: Narratives of factors that influence maternal non-disclosure of biological paternal identity. Johannesburg: University of the Witwatersrand 2013.

[3] Nduna M. Factors that hinder the disclosure of the biological identity of a father to a child: South African mothers' perspective. J Feminist Family Ther 2014; 26(4): 218-35.

[4] Kiernan K. Non-residential fatherhood and child involvement: evidence from the millennium cohort study. London, UK: Centre for Analysis of Social Exclusion: London School of Economics and Political Science 2005.

[5] Moore HL. Feminism and Athropology. Great Britain: Polity Press 1991.

[6] Nduna M, Jewkes R. Undisclosed paternal identity in narratives of distress among young people in the Eastern Cape, South Africa. J Child Family Stud 2011; 20(3): 303-10

[7] Datta K. "In the eyes of a child, a father is everything": Changing constructions of fatherhood in urban Botswana? Women's Stud Int Forum 2007; 30(2): 97-113

[8] Phaswana ED. Experiences of rural Black South African adolescents who never met their own biological fathers [MiniDissertation]. Johannesburg: Rand Afrikaans University 2003.

[9] Polela M. My Father, My Monster: A True Story. Auckland Park, Johhanesburg: Jacana Media 2011.

[10] Maathai W. The Challenge for Africa. London: Arrow Books 2010.

[11] Sirleaf EJ. This Child Will Be Great: Memoir of a Remarkable Life by Africa's First Woman President. New York: Harper Collins Publishers 2009.
[12] Ramphele M. Steering by the stars: Being young in South Africa Cape Town: Tafelberg 2002.

[13] Mavungu EM, Thomson-de Boor H, Mphaka K. "So we are ATM fathers": A study of absent fathers in Johannesburg, South Africa Johannesburg. Centre for Social Development in Africa: University of Johannebsurg 2013.

[14] Swartz S. IKASI: The moral ecology of South Africa's township youth. Johannesburg: Wits University Press 2009.

[15] Meerum Terwogt M, Meerum Terwogt-Reijnders CJ, van Hekken SMJ. Identity problems related to an absent genetic father. Zeitschrift fur Familienfirschung. 2002; 14(3): 257-71.

[16] Nkabinde NZ. Black Bull, Ancestors and Me: My Life as a Lesbian Sangoma. Auckland Park: Fanele-an imprint of Jacana Media (Pty) Ltd 2008.

[17] Nduna M, Sikweyiya Y. Silence in young women's narratives of absent, unknown and undisclosed fathers from Mpumalanga Province, South Africa. J Child Family Stud 2013; 1-10.

[18] Uys D, van Dulm O. The functions of classroom code-switching in the Siyanda District of the Northern Cape. Southern Afr Linguist Appl Language Stud 2011;29(1): 67-76.

[19] Stell G. Is there a Namibian Afrikaans? Recent trends in grammatical variation in Afrikaans varieties within and across Namibia's borders. Stellenbosch Papers Linguistics Plus 2009; 39: $85-105$.

[20] Nduna M, Sikweyiya Y, Khunou G, Pambo V, Mdletshe T. Ethical Reflections in Qualitative Research on Father's Absence: A South African Township Case-Study. In: Nakray K, Alston M, Whittenbury K, Eds. Social Science Research Ethics for a Globalizing World: Interdisciplinary and Cross-Cultural Perspectives. Routledge Advances in Research Methods: Routledge 2014; in press.

[21] Nduna M, Khunou G, Sikweyiya Y, Pambo V, Mdletshe T. Vicarious and Secondary Trauma in Interviews on Father Identity and Connections. In: Nakray K, Alston M, Whittenbury K, eds. Social Science Research Ethics for a Globalizing World: Interdisciplinary and Cross-Cultural Perspectives: Routledge 2014; in press.

[22] Spiegel AD, Mehlwana AM. Family as a social network: Kinship and sporadic migracy in the Western Cape's Khayelitsha. Cape Town: Department of Social Anthropology, University of Cape Town: Co-operative Research Programme on Marriage and Family Life 1997.

[23] Bhimsan R. Implications of the new air quality bill on the managemnet of $\mathrm{H}_{2} \mathrm{~S}$ emissions from Sasol's operations in Secunda, South Africa. Pretoria: University of Pretoria 2005.

[24] Durbach A. Upington: A story of trials and reconciliation. Cape Town, South Africa: David Philip Publishers 1999.

[25] Statistics South Africa: Census 2001. Concepts and Definitions. Pretoria: South Africa: Statistics South Africa, 2004 Contract No.: Report No. 03-02-26 (2001).

[26] Maré G. Brothers born of warrior blood: politics and ethnicity in South Africa. Johannesburg: Ravan Press 1992.

[27] Jewkes R, Nduna M, Levin J, et al. A cluster randomizedcontrolled trial to determine the effectiveness of stepping stones in preventing HIV infections and promoting safer sexual behaviour amongst youth in the rural Eastern Cape, South Africa: trial design, methods and baseline findings. Tropical Med Int Health 2006; 11(1): 3-16.

[28] Sands RG. Narrative Analysis: A feminist approach. In: Padgett DK, ed. The Qualitative Research Experience. Toronto, Canada: Thomson, Brooks/Cole 2004; pp. 48-78.

[29] Jewkes R, Sikweyiya Y, Nduna M, Jama Shai N, Dunkle K. Motivations for, and perceptions and experiences of participating in, a cluster randomised controlled trial of a HIV-behavioural intervention in rural South Africa. Culture, Health \& Sexuality 2012. Epub 14 Sep 2012.

[30] Emanuel EJ. Ending concerns about Undue Inducement. J Law Med Ethics 2004; 32: 100-5.

[31] Grady C. Money for research participation: Does it jeopardize informed consent? American J Bioethics 2001; 1(2): 40-4

[32] Clowes L, Ratele K, Shefer T. Who needs a father? South African men reflect on being fathered. J Gender Stud 2013.

[33] Bank LJ. Home spaces, Street styles: Contesting power and identity in a South African City. New York and Johannesburg: PlutoPress and Wits University Press 2011 
[34] Mosoetsa S. Eating from one pot: The dynamics of survival in poor South African households. Johannesburg: Wits University Press 2011.

[35] AVERT. South Africa HIV \& AIDS Statistics [cited 201318 March]. Available from: http: //www.avert.org/south-africa-hivaids-statistics.htm.

[36] Statistics South Africa. Mid-year population estimates 2011. In: Africa SS, Ed. Pretoria 2011.

[37] groundWork. Sasol lists on the New York Stock Exchange Pietermaritzburgyear unknown [cited 201330 April]. Available from: http: //www.groundwork.org.za/Pamphlets/Sasol us.pdf.

[38] Nduna M, Jama N. Steps to Sexual Equity. Siyaya. 2001; vol. 8: pp. 32-3.

[39] Makiwane MB, Makoae M, Botsis H, Vawda M. A baseline study on families in Mpumalanga. Human Sciences Research Council,
Pretoria: Human and Social Development, Population Health, Health Systems and Innovation. CeSTii 2012.

[40] Bojuwoye O, Akpan O. Children's reactions to divorce of parents. Open Fam Stud J 2009; 2: 75-81.

[41] Holborn L, Eddy G. First Steps to Healing the South African Family. Johannesburg: South African Institute of Race Relations 2011.

[42] Mohale NF. The burden of grandparenting: caring for AIDSorphaned grandchildren in Lephalale, South Africa. Polokwane, Limpopo: University of Limpopo (Turfloop Campus) 2013.

[43] Wamhoff S, Burman S. Parental maintenance for children: How the private maintenance system might be improved. Social Dynamics 2002; 28(2): 146-76

(C) Mzikazi Nduna; Licensee Bentham Open.

This is an open access article licensed under the terms of the Creative Commons Attribution Non-Commercial License (http://creativecommons.org/licenses/ by-nc/3.0/) which permits unrestricted, non-commercial use, distribution and reproduction in any medium, provided the work is properly cited. 